Cad. Benjaminianos, Belo Horizonte, v. 13, n. 2, p. 295-313, 2017

\title{
A estética da obra de arte e do objeto na época da reprodução biopolítica
}

\section{The aesthetics of artwork and of the object in the age of biopolitical reproduction}

\author{
Tiago Amaral da Silva \\ Universidade Federal de Minas Gerais (UFMG), Belo Horizonte, Minas Gerais / Brasi \\ tiago.amara196@gmail.com
}

Resumo: O presente artigo tem como objetivo discutir como a estetização dos objetos cotidianos e a fusão entre obra de arte e mercadoria influenciaram os modos de reprodução das relações sociais desde o advento da segunda revolução industrial até a contemporaneidade. Baseado nos conceitos de aura e da estética da guerra apresentados por Walter Benjamin no ensaio A obra de arte na época de sua reprodutibilidade técnica, traça-se um panorama do avanço das estratégias biopolíticas praticadas pela sociedade da produção em massa e do hiperconsumo, e sua relação com o esforço histórico de estetização do capital. Discute-se, por fim, os artifícios de ressignificação do ofício da arte por intermédio de seu amálgama com objetos de fabricação serial de caráter perverso, e como tal processo é utilizado para a perpetuação do poder subreptício das sociedades de controle.

Palavras-chave: Biopolítica; estetização; obra de arte; sociedade de consumo.

Abstract: This paper intends to discuss how the aesthetization of everyday objects and the fusion between artwork and commodities induced the modes of reproduction of social relations since the second industrial revolution to the contemporaneity. Based on Walter Benjamin's concepts of aura and aesthetics of war, presented in his essay The work of art in the age of its technological reproducibility, it is outlined a picture of the progress of biopolitical strategies practiced by the society of mass production and hyper consumerism, as well as your relation with the historical effort of capital's 
aesthetization. Finally, it discuss the artifices of redetermination of the art craft by its merging with serial manufacturing objects who carry a wicked feature, and how this process is used to perpetuate a hidden power in the societies of control.

Keywords: Biopolitics; aesthetization; artwork; consumer society.

\section{Introdução}

Durante grande parte da história da humanidade, arte e objeto se encontravam plenamente dissociados. Os objetos caracterizavam-se como ferramentas, cotidianas e ordinárias, cuja função era a de realizar tarefas cuja execução não representava uma condição de excepcionalidade na vida de seus usuários. A obra de arte, em contraponto, era a manifestação de um contexto excepcional, de um momento que, por um dado motivo social, cultural ou religioso, transcendia a linearidade da rotina do indivíduo.

Nos primórdios da raça humana, a arte possuía caráter fortemente ritualístico. As pinturas paleolíticas, primeira manifestação artística e representacional do homem pré-histórico, estavam atreladas integralmente às crenças destes e a sua forma de visão do mundo. Isso quer dizer que estas obras de arte eram únicas, por estarem ligadas a um momento histórico e a um contexto social extremamente específico. Não é possível produzir arte paleolítica sem imbuir a esta os rituais realizados pelos homens paleolíticos. Walter Benjamin, desse modo, enuncia:

(...) o valor único da obra de arte 'autêntica' tem sempre um fundamento teológico, por mais remoto que seja: ele pode ser reconhecido, como ritual secularizado, mesmo nas formas mais profanas do culto do Belo. (BENJAMIN, 1987, p. 171).

A essa autenticidade e valor único da obra Benjamin atribui o conceito de aura. A aura é a singularidade de espaço, de tempo e de representação, cuja presença garantiu, até o início da modernidade, a autonomia da obra da arte.

Com o advento da segunda fase da revolução industrial, a lógica de produção - seja de objetos, do espaço ou de relações - se altera, com a serialização se sobrepondo cada vez mais ao artefato autêntico. A racionalidade da produção em massa sobrepõe-se à arte, diluindo desta sua dimensão de singularidade, seja ela de ordem religiosa, social ou cultural. Ainda que nos demais períodos históricos de transição - da pré-história à antiguidade, desta à idade média, e desta ao renascimento 
- houvesse significativas alterações das hierarquias de poder e das dinâmicas sociais, não se presenciou o efeito de mudança da dimensão produtiva do homem em termos laborais que o modernismo industrial promoveu. Há uma mudança do eixo de significação da arte, que antes se fixava em um referencial externo, seja ele o do culto, do mito, do clero ou do humanismo. Quando o referencial é a própria produção da obra, que se altera em seu termo mais crítico - o da autenticidade - há uma inflexão que torna sua caracterização insustentável:

O conceito de aura permite resumir essas características: o que se atrofia na era da reprodutibilidade técnica da obra de arte é sua aura. Esse processo é sintomático, e sua significação vai muito além da esfera da arte. Generalizando, podemos, dizer que a técnica da reprodução destaca do domínio da tradição o objeto reproduzido. Na medida em que ela multiplica a reprodução, substitui a existência única da obra por uma existência serial. (BENJAMIN, 1987, p. 168).

A aura, que antes era incorporada à obra de arte pela mão do artista, no período da revolução industrial se desfaz pela impessoalidade imposta, seja pelo desmembramento do processo de produção, seja pela substituição do trabalho humano pela força da máquina. Ainda que esta seja uma lógica específica desse momento histórico e com um contexto social característico, não se pode dizer que as obras produzidas nessas condições são obras de arte industriais. As obras industriais são exatamente o oposto da obra de arte: são o produto da massificação da produção e da propagação expandida de um objeto destituído de caráter único. A obra industrial, ao ser produzida por uma força de trabalho coletiva não torna-se obra de arte coletiva, mas obra de significado nulo. Para William Morris, "A arte é a expressão da alegria do homem no trabalho" (MORRIS, 2003, p. 25), e o trabalho industrial, por meio da racionalização extrema, esmaga qualquer vestígio de deleite incorporado no ofício do indivíduo.

Produzido pela força de trabalho das massas em escala abrupta, logo percebe-se que este excedente produtivo de obras deve se voltar para as próprias massas. Além de ampliar o potencial produtivo da arte até esvaziar seu sentido de unicidade, a lógica do capital precisa banalizá-la de modo que possa ser acessada por todos. A arte precisa, então, fundir-se ao objeto. Dessa confluência surge o design: um desenho - com caráter de obra esvaziada - que designa um objeto, cuja produção, serializada, 
racional e industrializada, pode ser reproduzida e comercializada em larga escala. A similaridade entre categorias antes díspares é tanta que, nas artes de vanguarda, a aura torna-se um anacronismo: Os readymades de Marcel Duchamp equalizam objetos do cotidiano às obras de arte consagradas, expostas em museus. Esta radicalização proposta pelo artista plástico apenas evidencia que a linha entre objeto e arte, na modernidade, é sensivelmente tênue.

Da modernidade à hipermodernidade - ou pós-modernidade, em termos correntes - veremos adiante que a aura não é só desmontada, mas pode ressurgir como método de evidenciação conforme os interesses da lógica capitalista. A produção de obras de arte não se resume mais à cristalização do impulso artístico, mas na imposição de um meio de promoção da singularidade como status social. Por outro lado, a fusão arte-objeto se intensifica ainda mais naqueles pontos críticos onde a ofensividade de um dos lados pode ser suavizada pelo viés estético do outro.

Este último viés será analisado com mais detalhes no capítulo 5, por intermédio de um estudo de caso elaborado na cidade de Belo Horizonte. Neste estudo, será possível analisar como a intrusão da dimensão de uma estética do belo - providenciada pela obra de arte - em objetos de caráter defensivo geram uma genuína estética da guerra, tal como preconizada por Walter Benjamin (1987). A produção deste contexto reflete-se no espaço urbano à medida que tais obras ressignificadas pela estética, e em interação com o homem, formam cidades em estado de sítio. Contudo, tal estado reproduz-se não como excepcionalidade, mas como modus operandi da vida contemporânea.

\section{0 design na era da máquina}

O sistema de produção Fordista, quando implantado, significou uma mudança estrutural dos meios de produção, fazendo sobrepor a dimensão da quantidade sobre a da qualidade do que era produzido. A serialização e a massificação dos objetos confeccionados fizeram com que se perdesse o gesto artístico aplicado pela mão do artesão. A linha de produção, deste modo, foi um artifício bem-sucedido na tarefa de multiplicar os excedentes produtivos e diluir o saber-fazer do ofício artesanal e autoral.

Em seu livro Origens da arquitetura moderna e do design, Nikolaus Pevsner (1981) traça um panorama dos caminhos da ideologia 
artística durante a segunda metade do século XIX e o início do século $\mathrm{XX}$, até alcançar a modernidade industrial. O autor demonstra nesse contexto a aplicação de novos materiais à arquitetura - nomeadamente o ferro e o vidro - e como essa revolução permitiu o surgimento de um novo estilo, o Art Nouveau.

As formas desta nova corrente ainda inspiravam uma artesania apurada, mas promoviam uma quebra de paradigma ao incorporar nas artes e arquitetura uma escala gregária. A representação e destinação da arte deslocam-se da igreja e da sociedade de alto poder aquisitivo para uma classe média que agora tem para si o desenho da casa, do objeto e até mesmo da tapeçaria. Não é por acaso que William Morris, o mesmo que retrata a arte como expressão do prazer no trabalho, possui nesse período sua produção mais prolífica, confeccionando tecidos e mobiliários inteiramente manufaturados. Neste sentido, ele denuncia seus contemporâneos afirmando que os grandes arquitetos do século XIX viviam uma vida “(...) afastada dos problemas comuns do homem comum” (MORRIS, 1910, p.41 apud PEVSNER, 1981, p. 28). Os arquitetos a quem Morris dirige sua crítica dispensavam tempo projetando igrejas, edifícios públicos, casas de campo e mansões para os ricos, atitude que teve uma mudança gradual com o direcionamento da artesania para o âmbito da construção doméstica (PEVSNER, 1981, p. 28).

Quando anos mais tarde, em 1910, Adolf Loos publica sua mais conhecida obra, Ornamento e crime (LOOS, 2004), ele subverte todo o empenho aplicado anteriormente a este trabalho manual. Ao mesmo tempo ele catalisa, indiretamente, a massificação do objeto e da obra de arte. Neste livro, Loos defende que o ornamento é antieconômico e sinal de depravação da sociedade. Desse modo, o design deveria adotar um aspecto asséptico, de formas racionais e elementares, como se essa pureza de representação se transferisse para o aspecto comportamental da sociedade. Com tal premissa o arquiteto desconsidera todo o impulso de autenticidade e de vestígio aurático que seria transferido, por intermédio da mão, a uma obra de caráter artisticamente decorativo. Sabe-se que, mais tarde, com a plena instauração do movimento moderno, o predomínio de formas racionais e desprovidas de ornamentação não implicou na extinção da autoria, mas, levando em conta a época na qual estava inserido, Loos promoveu uma grande mudança intelectual e estilística.

Para a produção industrial que focava o rendimento, as ideias propostas por Loos foram providenciais. A extinção do ornamento 
significava a extinção do trabalho de caráter individual e específico, perpetuando o racionalismo da forma. Os objetos passarem a ser impessoais e desprovidos de personalização, podendo ser replicados indefinidamente, por uma força de trabalho que não precisava dispensar impulso criativo em sua realização. $\mathrm{O}$ esforço da produção, que poderia então perpetuar-se ad infinitum precisava apenas de uma contraparte: a destinação do que era elaborado. Indústria e consumo foram, assim, forças complementares, que passaram a se sustentar mutuamente. Este consumismo, cujo crescimento acompanharia a corrida exponencial experimentada pela produtividade, e seus efeitos no estilo de vida e visão de mundo de seus usuários serão abordados detalhadamente no próximo capítulo.

Antes, entretanto, é necessário mostrar como a função do objeto e sua estetização pela arte se intensificaram na dimensão produtiva em relação à outra mudança de paradigma histórico: a segunda guerra mundial. Com o arrasamento da Europa no pós-guerra, foi necessário reconstruir uma sociedade de forma rápida, eficiente e barata. A partir desse contexto, o design, já bastante racionalizado pelo impulso antiornamental de Loos, adotou uma estética da sobriedade. Os objetos passaram a ser desenhados de modo a terem a maior eficiência e funcionalismo possível, com linhas simples e economia de material. Nesse mundo alterado por um evento de tal magnitude e horror, excessos de consumo não faziam mais parte da realidade dos indivíduos, pelo menos não em curto prazo.

De modo totalitário e impositivo, há movimentos que enxergaram nesta alteração social ocasionada pela guerra e na planificação do design uma vantagem, e, não obstante, a veneravam. É o caso da vanguarda futurista, de Filippo Tommaso Marinetti (1980), cujo manifesto escrito em 1909 em tom fascista, agressivo e misógino, louva o advento da máquina e a velocidade como vetores de modernização progressiva e inexorável da humanidade. A antiguidade clássica e a obra de arte em sua acepção esteticamente bela foram dadas como superadas, e aludidas como sinal de primitivismo em uma sociedade evoluída. Segundo Marinetti:

Um carro de corrida cuja capota é adornada com grandes canos, como serpentes de respirações explosivas de um carro bravejante que parece correr na metralha é mais bonito do que a Vitória da Samotrácia. (MARINETTI, 1980, p. 32). 
Evidencia-se, assim, que a ideologia que os futuristas cultuavam não almejava apenas a fusão entre arte e indústria, mas a sobreposição completa e esmagadora desta última sobre a primeira. Para alcançar o estado de êxtase da sociedade hiperindustrial, a estética futurista pregou a imbricação completa da máquina em todas as instâncias da vida do indivíduo. Tal estado remete ao conceito de obra de arte total (Gesamtkunstwerk), podendo ser caracterizada como uma das primeiras manifestações de uma estética totalizante unindo arte e objeto (no caso, a máquina).

Outra tentativa de aplicação estética totalizante - e com êxito maior que a dos futuristas - foi o movimento moderno de Le Corbusier. Em Por uma arquitetura (1977), o arquiteto leva o funcionalismo na arquitetura a seu ponto extremo, caracterizando a casa como a máquina de morar (LE CORBUSIER, 1977, p. 73). Nas suas propostas de planejamento urbano, a setorização da cidade também deve ocorrer através de seus usos: habitar, trabalhar, recrear e circular. Em suma, o que o modernista propõe é uma experiência completa - e em escala urbana - que determina os modos agir no espaço, estabelecendo relações de produção e de uso programadas.

A arquitetura e o planejamento moderno ressoam ainda hoje como métodos de aplicação do funcionalismo e da lógica fordista aos indivíduos. Entretanto, o que estes métodos não lograram êxito foi na unificação desta prática com uma estética globalizante, que não dissocia funções, tipos ou hierarquias de relações, agindo de modo subreptício no cotidiano. Essa estética, que controla não só a ação como o corpo - individual e social - só foi consolidada no pós-modernismo, como veremos no capítulo 4.

\section{Sociedades de consumo e sociedades do espetáculo}

$\mathrm{O}$ advento da máquina entre o fim do século XIX e o início do século XX trouxe, mais que uma revolução no caráter quantitativo da produção, uma nova forma de vida. A automatização do trabalho cotidiano e a massificação dos objetos traziam agora o conforto, a segurança e o bem-estar da humanidade - ou pelo menos da parte dela que não sofria espoliação direta de sua força de trabalho - dando a impressão de que o progresso dali em diante se estenderia eternamente. Nesse período, Walter Benjamin experimentou viver no locus da sociedade de consumo, a capital econômica, cultural e catalisadora da efervescência da nova sociedade de culto do dinheiro: a cidade de Paris. 
Entre 1927 e 1940, Benjamin escreve aquela que foi sua mais extensa obra: Passagens (2007). Referência direta a uma nova modalidade de espaço que florescia em Paris, as passagens eram os locais de concentração comercial da cidade, onde, pela primeira vez na história, o consumo possuía um espaço de exposição e de fruição. O princípio da imageabilidade era indispensável nas passagens: as vitrines, os vendedores, as estruturas inovadoras de ferro e vidro: todas as condições fluíam para uma experiência estética voltada para a circulação de bens econômicos. O poder de aquisição nunca fora tão aprazível e tão acessível antes na história da humanidade. As passagens eram, assim, forma obrigatória de desfrute citadino, que consumavam, acima de tudo, a passagem do tempo, do espaço e do capital.

A magnificência da sociedade parisiense de fins do século XIX e a obra de Benjamin terminam em um trágico ponto de convergência: a ascensão dos governos fascistas na Europa e a deflagração da Segunda Guerra Mundial. O horror desses eventos de demonstração de soberania política das potências trouxe consigo tempos de economia e racionamento, mas não marcou um fim precoce das sociedades de consumo. Quando do fim deste período sombrio, e com uma vitória expressiva dos Estados unidos da América, a cultura da mercadoria volta com toda força sob a égide do american way of life. Nesse contexto, as passagens ressurgem em uma encarnação mais complexa e diversificada: as lojas de departamentos, que elevam o capital a um novo patamar:

A figura mais imediatamente visível, identificada, observada, comentada, que lança o capitalismo em sua aventura artista é inegavelmente a loja de departamentos. A grande distribuição, encarregada de escoar os artigos padronizados, se impôs bem cedo, através desta, como um espetáculo fulgurante de beleza, teatralidade e luxo. O capitalismo de consumo inventou e multiplicou novos espaços estéticos: "templos" das compras que, combinando comércio e mise-en-scène, deram o pontapé inicial do capitalismo artista. (LIPOVETSKY; SERROY, 2015, p. 95).

Agora, somente o consumo não é mais suficiente, é necessário o excesso. A circulação de bens, imagens e relações alcançam uma velocidade tal que sua riqueza não consiste mais em seu conteúdo, mas na sua saturação. $O$ prazer reside numa sociedade baseada na renovação incessante e repetitiva de bens, uma sociedade do espetáculo, onde 
qualidade de vida quer dizer quantidade de aparências que se pode ostentar. "O espetáculo é o capital em tal grau de acumulação que se torna imagem" (DEBORD, 1997, p. 25), já nos alertava Guy Debord sobre como um sistema econômico até então pautado pela exploração extensiva do proletariado se tornou sorrateiramente uma sociedade da fruição por meio de uma estetização ampla do estilo de vida. Afirma ainda que:

O espetáculo é o momento em que a mercadoria ocupou totalmente a vida social. Não apenas a relação com a mercadoria é visível, mas não se consegue ver nada além dela: o mundo que se vê é o seu mundo. (DEBORD, 1997, p. 30).

Quando os objetos, imbuídos pelo potencial estetizante da obra de arte, tomam a sociedade do espetáculo como totalidade, é pela sua via de negociação, a do consumo, que passam a se pautar as relações entre indivíduos. O caráter do consumo passa de um nível de mero atendimento de necessidades do homem para o de um meio complexo de legitimação de sua posição social. O status não é mais obtido por meio de títulos, ou pela validação de instituições seculares, mas sim pelo potencial de propriedade que os indivíduos carregam.

Desse modo, o capital passa a ser instrumento de consolidação de desigualdades sem nem mesmo precisar do estabelecimento de barreiras físicas. A distinção pela posse gera, por si só, diferenciações sociais que ratificam a segregação no espaço. Para o sociólogo francês Pierre Bourdieu (2013, p. 137), o capital é o mais eficiente instrumento de distanciamento socioespacial entre os estratos populacionais. Ser possuidor do capital lhe permite se aproximar de posições e pessoas que o interessem, ao mesmo tempo em que o mantém longe dos aspectos indesejáveis. Posse de capital, nesse sentido, equivale à posse da acessibilidade facilitada, espacialmente e temporalmente, às condições adequadas e desejáveis socialmente. Em contrapartida, ser desprovido de capital the mantém afastado dos bens de consumo raros e desejáveis, o distanciando das condições de interesse da sociedade.

A essa construção social e simbólica das classes e indivíduos promovidos pelo capital e transpostas a sua posição espacial e hierárquica, Bourdieu dá o nome de habitus. Abordado na obra A distinção - crítica social do julgamento (BOURDIEU, 2007), o conceito de habitus defende que aspectos culturais e do estilo de vida dos indivíduos definem seu posicionamento na hierarquia social (BOURDIEU, 2007). A segregação, 
portanto, estabelece-se pelos modos de vida que o capital de consumo, ou a ausência deste, impõe-se na cotidianidade do sujeito: o modo de agir, de se comunicar, o que come, o que veste e os locais que frequenta. Posição social, portanto, está intrinsecamente ligada a uma construção estética do ser, cuja comercialização, encarnada na imagem, é a principal moeda de transação da sociedade do espetáculo.

Para os que podem arcar com a aquisição de um modo de vida esteticamente fabricado pelo capital, a distinção social se estabelece pelo gosto. Estar na moda, adquirir itens luxuosos e únicos, fazer parte de um círculo social prestigiado: o capital criou simulacros de vida desejável que partem antes do ter que do ser. Aos que não participam deste circuito, resta o ordinário, o comum, sendo o simples direito de escolha entre o feio e o belo sobrepujado pela necessidade.

Em sociedades hedonistas e exibicionistas, o modus operandi do consumo e do espetáculo fazem com que a autenticidade e exclusividade das obras não sejam mais dadas em função da aura de seu autor, mas da posição social para a qual se direcionam e do status que podem inspirar.

\section{Biopolítica e a estetização do mundo}

A condição pós-moderna é definida por Harvey (1992), Lyotard (1998), Dardot e Laval (2016) e outros autores como o período onde ocorre a flexibilização do capital produtivo e acirramento do individualismo e competitividade dos sujeitos. A maleabilidade das formas de produção e consumo e a atomização do corpo social permitem o surgimento de um sistema de controle atuando sobre a coletividade e o indivíduo: a biopolítica.

Em Foucault, a biopolítica surge como uma prática de poder que se foca no conjunto dos indivíduos, sobre os quais, enquanto coletividade, serão direcionados os métodos de controle. Este "movimento que faz aparecer a população como um dado, como um campo de intervenção, como o objeto da técnica de governo" (FOUCAULT, 1979, p. 265), aplica o poder como tecnologia, como modo de gestão dos costumes cotidianos, ou seja, como modo de gestão da vida. Estabelece-se, assim, um governo dos hábitos e da dominação dos corpos (no sentido biológico).

As novas formas de controle por meio de uma coletivização do indivíduo demandam uma reinvenção também dos sistemas de consumo, cujo domínio social deve ter o poder de infiltrar-se neste corpo social global. Surge assim o capitalismo artista como a nova esfera de 
contaminação dos objetos do cotidiano pela arte, iniciada na sociedade de consumo do século XIX. Jean Serroy e Gilles Lipovetsky apontam em A estetização do mundo (2015) como o sistema Fordista falhou em promover um consumismo constante ao limitar-se apenas à produção desenfreada, sendo superado pelo hiperconsumismo, onde as experiências e a imageabilidade atreladas aos produtos impulsionam a perpetuação da necessidade de aquisição de bens.

O capitalismo artista corresponde precisamente a nossa contemporaneidade, cujo fluxo desenfreado de consumo, experiências, imagens e relações a definem como uma hipermodernidade. Nesse cenário ocorre a hibridização das dimensões do viver, totalmente oposta às funções que Le Corbusier propôs no século XX. As diferentes instâncias da nossa rotina se fundem de tal modo que não é mais possível separar trabalho do ócio e do lazer, vida pública da vida privada. Somos subordinados a uma transestética que esvazia, pelo excesso, nossos gostos e experiências:

O capitalismo artista é o sistema em que são desestabilizadas as antigas hierarquias artísticas e culturais, ao mesmo tempo em que as esferas artísticas, econômicas e financeiras se interpenetram. Onde funcionavam universos heterogêneos se desenvolvem processos de hibridização que misturam de maneira inédita estética e indústria, arte e marketing, magia e negócio, design e $\mathrm{cool}$, arte e moda, arte pura e divertimento. (LIPOVETSKY; SERROY, 2015, p. 34).

Vivemos na época em que todo objeto, de uma garrafa de água ao mais moderno automóvel no mercado, possuem designs singulares. $\mathrm{O}$ capitalismo artista não vende apenas produtos estandardizados em uma linha de produção, mas modos de vida e de identidade estética. O controle das massas não se dá por um estado onipresente e autoritário, mas por megaempresas que estão presentes no nosso trabalho, na nossa casa e no nosso lazer. Sob um só símbolo concentramos nossos dados, eletroeletrônicos, utensílios, e mais importante que isso, nossa personalidade. O capitalismo não é mais somente um sistema econômico, mas um sistema de existência.

Pela biopolítica a estética pode, de fato, exercer sua dimensão totalizante. Isso não ocorre pela força fascista, como previu Marinetti, ou pelo planejamento urbano funcionalista, ao modo de Le Corbusier. 
Ocorre pela intrincada e estruturada naturalização do consumo como prática inerentemente humana, por intermédio de uma banalização da arte como artifício embelezador das relações de reprodução do capital.

Estabelecida a sociedade da hipermodernidade e da biopolítica, resta saber como se comportam as relações e as dinâmicas estabelecidas por tais conjunturas quando transpostas no espaço. E o único lugar capaz de comportar a estrutura complexa de conexões efetuadas na sociedade do espetáculo e da transestética é o fenômeno urbano, ou seja, a cidade.

Do ponto de vista do neoliberalismo, onde predomina o consumismo, podemos definir a cidade como locus da produção e da concentração do trabalho e das relações humanas. A aglomeração urbana resume-se, portanto, à criação, sobretudo criação de obras (LEFEBVRE, 2016 , p. 8). O desenvolvimento das cidades, desde o paradigma da revolução industrial vem sendo composto pelo agenciamento entre estas obras e os indivíduos. A estetização dos objetos, frutos do trabalho humano, tem o poder de desestabilizar a balança que equaliza seus vínculos relacionais. Portadores da agência e com a aparência estetizada, os objetos são capazes, agora, de exercer modificações na percepção do homem e de seu modo de vivência no espaço. A hipermodernidade anima os objetos ao passo que reifica os indivíduos.

\section{Estética da beleza e estética da segurança: muros como paradigma da estetização hipermoderna}

Durante os anos de 2015 e 2016, foi desenvolvida na Escola de Arquitetura da Universidade Federal de Minas Gerais, no âmbito do grupo de pesquisa Narrativas topológicas, a pesquisa de iniciação científica voluntária Arquitetura da violência: o muro como limiar estético da vida nas cidades. Sob a premissa da guerra como continuação da política à medida que rebate as relações de poder no espaço urbano (FOUCAULT, 2005 , p. 41), a pesquisa teve como objetivo desmistificar o grau de agência de um objeto que é originado pelo labor humano e tem interface direta com suas relações sociais: o muro.

Elementos comuns na nossa realidade urbana, os muros são responsáveis, a princípio, por estabelecer os limites da propriedade privada e garantir a segurança da mesma. Entretanto, no campo da transestética, estes artefatos não se resumem a sua funcionalidade original. Os muros podem ser concebidos como obras de arte integrantes 
de uma estética específica: a da guerra. Como tal, são significantes bastante enfáticos de posição social e de status.

$\mathrm{Na}$ pesquisa foram estudados bairros localizados nas nove regionais administrativas de Belo Horizonte, de modo a analisar como o elemento muro se comporta em diferentes territorialidades e contextos sociais. A eles, aplicaram-se duas metodologias, que complementarem-se pelo seu caráter antagônico: um levantamento de dados objetivos e uma análise da percepção subjetiva.

A primeira metodologia foi a elaboração de um inventário urbano focado nos muros, grades e barreiras encontrados pelos bairros. O levantamento destes elementos foi realizado por meio de fotografias autorais, seguindo sempre uma padronização de representação. Esta uniformização dos registros permitiu gerar parâmetros para elencar, comparativamente, os aspectos construtivos, contextuais, sociais e até mesmo filosóficos dos muros. A segunda metodologia constituiu-se pela aplicação do método da Deriva Perceptiva, pautando-se nos estudos situacionistas propostos por Guy Debord 1 . A deriva foi essencial para desvelar as qualidades do espaço enquanto o pesquisador encontrava-se inserido e experienciava o mesmo. Nessa posição, importava perceber o muro como resultado de uma experiência estética e investigar sua influência na composição do espaço urbano e como gerador de sensações e juízos pessoais no indivíduo.

Da aplicação destes procedimentos, juntamente à associação de informações legais, históricas e dos contextos socioculturais dos bairros estudados, foram concebidas hipóteses sobre o espaço urbano a partir do muro. Dentre tais especulações destaca-se uma que estabelece um fio-condutor para as demais, e cujo emprego, em certa medida, aplica-se a todos os contextos estudados sob o prisma da estetização do espaço que se ressaltou na hipermodernidade. Seria uma relação entre o que se nomeou de Estética da beleza e Estética da segurança.

\footnotetext{
${ }^{1}$ Para mais detalhes sobre a Internacional Situacionista e os métodos de experimentação da cidade propostos Guy Debord e outros adeptos do pensamento situacionista, ver o livro organizado por Paola Jacques Berenstein: Apologia da Deriva (2003). Nele, são apresentados conceitos como a Teoria da deriva e o Urbanismo psicogeográfico, práticas que visam um novo modo de experimentação do espaço urbano baseado nos estados psíquico e emocional dos usuários.
} 
Em princípio, o muro, na sua acepção puramente funcionalista, atende a uma Estética da segurança. Seria, portanto, um elemento que atua como barreira e ferramenta de delimitação do espaço, promovendo a segregação entre o espaço público e o privado. Para exercer esse papel, o muro não necessita de adornos, muito menos inspirar simpatia ou catarse a quem o contempla. Quando muito, deve apenas demonstrar solidez e intransponibilidade, ou adições que reforcem sua instrumentalidade agressiva, como os ofendículos, que vão de pontas de lança a cercas elétricas. A Estética da segurança isolada deve, portanto, demonstrar que o elemento é pragmático e cumpre com eficiência sua tarefa de proteção e isolamento.

Há, entretanto, contextos urbanos nos quais o limiar entre público e privado não necessita ocorrer de forma tão abrupta. Constatou-se que, predominantemente em bairros de maior poder aquisitivo ou onde há elementos de notável interesse para o patrimônio cultural e histórico, o muro funciona antes como elemento compositivo da arquitetura e do contexto que como barreira. Atende, assim, ao que se nomeia Estética da Beleza. O muro é aqui um elemento que, através de adições decorativas, compõe a fachada, ou, por meio do uso de vidro e maiores aberturas, promove permeabilidade visual e funciona como expositor. Importa não mais proteger-se, mas ostentar: $\mathrm{O}$ elemento que antes isolava é agora suporte para estabelecer um demonstrativo de posição social e de integração com o público. A imageabilidade exerce, nesse contexto, muito mais poder que uma expressão de belicismo puro.

Entretanto, a aplicação de uma estética somente da beleza ou somente da segurança só era possível na sociedade moderna do contexto funcional e fordista, a qual o filósofo francês Gilles Deleuze caracteriza como sociedade disciplinar. Na conjuntura onde os meios de confinamento eram instituições organizadoras da sociedade, as barreiras como segurança eram o modo mais naturalizado de ordenamento. Logicamente, nestas circunstâncias qualquer muro que se objetivasse por ser belo seria evidentemente discrepante do padrão vigente. A estetização do mundo que vimos surgir com a neoliberalização pós-moderna e a biopolitização da vida transpôs essa dicotomia. Na contemporaneidade, estética da segurança e da beleza estão intrinsecamente ligadas, formando uma nova categoria de sociedade que agora é definida pelo consumo, pela efemeridade das relações associada a uma continuidade da submissão do cotidiano à vida alienada. É o que Deleuze chama de sociedade de controle: 
Nas sociedades de disciplina não se parava de recomeçar (da escola à caserna, da caserna à fábrica), enquanto nas sociedades de controle nunca se termina nada, a empresa, a formação, o serviço sendo os estados metaestáveis e coexistentes de uma mesma modulação, como que de um deformador universal (...). O marketing é agora o instrumento de controle social, e forma a raça impudente dos nossos senhores. O controle é de curto prazo e de rotação rápida, mas também contínuo e ilimitado, ao passo que a disciplina era de longa duração, infinita e descontínua. O homem não é mais o homem confinado, mas o homem endividado. (DELEUZE, 1992, p. 221-224).

O muro que é ao mesmo tempo belo e seguro incorpora-se ao cotidiano de tal forma que não é mais possível distinguir suas instâncias funcional e decorativa. Câmeras de vigilância, sensores de presença, controle biométrico, blindex: elementos comuns das proteções que cercam nossas casas e que são considerados desejáveis, e mais ainda, a última tendência arquitetônica a ser seguida pelo indivíduo. A essa fusão das estéticas, cria-se uma nova, que alinha cegamente as massas com os interesses de um controle social disfarçado de bom gosto. Walter Benjamin define este estado de transe como a Estética da Guerra:

(...) os movimentos de massa e em primeira instância a guerra constituem uma forma de comportamento humano especialmente adaptada ao aparelho. As massas têm o direito de exigir as mudanças das relações de propriedade; o Fascismo permite que elas se exprimam, conservando, ao mesmo tempo, essas relações (...). 'Fiat ars, pereat mundus', diz o fascismo e espera que a guerra proporcione a satisfação artística de uma percepção sensível modificada pela técnica, como faz Marinetti. É a forma mais perfeita do art pour l'art. (BENJAMIN, 1987, p. 196).

O ideal de uma humanidade que incorpora ao seu cotidiano a beligerância de um estado de guerra permanente, que tanto desejava Marinetti com o movimento futurista, parece agora ter sido alcançada. Não da maneira imaginada, com uma manifestação explícita um tratamento fascista e agressivo no convívio social, mas por meio da incorporação da sua lógica no objeto comum e sua artesania inerente. A beleza e a arte de nossos dias são transcritas cada vez mais para a legitimação de um estado de controle coletivo e discreto, validado no consumismo. 


\section{Considerações finais}

O esvaziamento gradual da aura da obra de arte iniciado no período industrial e seu paulatino entrelaçamento com o objeto tem pautado o estado das relações de produção e consumo da pósmodernidade. Entender essa dinâmica é essencial para uma cartografia da sociedade contemporânea no campo das suas formas de controle cada vez mais biopolíticas. Os objetos, alicerçados nas formas de difusão do consumismo hipermoderno, são peças essenciais do processo de agência e formação de relações que o capitalismo artista constrói sobre a reprodução do espaço e da sociedade.

É necessário, entretanto, frisar que o esvaziamento da aura relevante para as sociedades de consumo contemporâneas está relacionado com a escala do cotidiano e da produção do comum, campo que no estágio histórico anterior era dominado pelo artefato industrial e pela artesania. A solução para desalienar a gestão da sociedade como massa de consumo não perpassa, portanto, pela revigoração da aura da arte, ou em outras palavras, por uma retomada da autenticidade da obra. A autoria e a iconicidade das grandes artes ainda continua vigente, configurando um star system restrito a poucos e que movimenta um mercado bilionário por intermédio da "Renda da forma" ${ }^{2}$. Este campo de arte elitizado faz parte de um circuito econômico superior que muito pouco influencia nos objetos e manifestações da obra de arte na escala das massas e do banal, cujo enfoque ressoa diretamente no sistema de poder das sociedades de controle biopolíticas.

A artesania étnica e popular na atualidade sobrevive como única manifestação da obra de arte autoral que ainda não sofreu um processo de esvaziamento da autoria. Por serem confeccionadas, na maior parte das vezes, em contextos comunitários e locais, também possuem uma influência muito maior sobre o cotidiano e as relações de uso e necessidades dos indivíduos que as produções de objetos massificados ou do star system.

Entretanto, na sociedade do excesso que nos situamos, essas manifestações de arte são esmagadas pelas produções vigentes, que

\footnotetext{
${ }^{2}$ Para um estudo detalhado sobre a renda da forma e o mercado de arte do star system no campo da arquitetura, ver o livro de Pedro Fiori Arantes: Arquitetura na Era digital-financeira: Desenho, Canteiro e Renda da Forma (2012). Para um estudo deste mercado relacionando arquitetura, artes plásticas e cinema, ver o livro de Hal Foster: O complexo arte-arquitetura (2017).
} 
possuem alcance físico e simbólico muito mais amplo. São, assim, caracterizadas pelo status quo como "artes menores" e manifestações folclóricas restritas a seu contexto social, que não contribuem para a consolidação de um patrimônio global e massificado. A opressão dessas expressões étnicas e comunitárias que se encontram fora do circuito de consumo é hoje muito combatida por um movimento que clama pelo estabelecimento de uma genealogia de saberes periféricos. Mas, ainda que sua importância tenha vindo cada vez mais à tona, é inegável que ainda se configura em nossa sociedade um extensivo apagamento das identidades culturais minoritárias.

Quando o objeto mescla-se com a obra de arte para formar uma estética e torna-se serial, ele torna-se nada mais que um produto. Como produtos, as obras são objetos de troca, esvaziados de valor social. Em outras palavras, objetificar a arte e embelezar o objeto fez com que ambos destes elementos perdessem seu sentido de transmissão histórica, cultural e política. As mercadorias contemporâneas são, assim, artefatos impessoais e despolitizados, que não inspiram no sujeito nenhum resquício de identidade.

Como campo de fuga, a autonomia surge como alternativa. Dar ao sujeito a noção de que ele pode produzir obras fora do circuito formal de produtivismo é uma forma de quebrar a impessoalidade e a planificação dos objetos provindos do capitalismo produtivo. Deve-se ressaltar que a produção de mercadorias em si não é colocada aqui uma perversidade que aliena irremediavelmente o consumidor. Interessa mais aplicar a autonomia no sentido de uma postura crítica que deseja enxergar nestas mercadorias, ou obras produzidas fora destes padrões de consumo, uma identidade própria. Identidade essa que não deve ser utilizada como instrumento de autenticidade para a perpetuação de status sociais, mas sim como meio de utilizar os objetos como receptáculos da ação do homem e de aplicação de seu trabalho social e cultural, a ser repassado para a posteridade. Autonomia de criação de obras é, então, autonomia na produção de objetos fruto da expressividade humana em seu contexto identitário e cotidiano.

Deve-se, entretanto, atentar para o fato de que a biopolítica, como sistema social, abrange em uma escala mais ampla a estruturação do sistema que pauta o consumo e a estetização da rotina do sujeito. Não se pode ser ingênuo e afirmar que a autonomia da produção de obras é o meio pelo qual se formará uma práxis revolucionária capaz de causar o colapso das sociedades de controle. Entretanto, o estabelecimento de tais fissuras, e mais que isso, a desmistificação dos processos de 
ressignificação da arte e do objeto realizados pelo capitalismo artista são formas de explicitar as estratégias do controle sociopolítico. Se Benjamin defendia a politização da arte como resposta à estetização da política realizada pelo fascismo (1987, p.196), deve-se responder a estetização do consumo realizado pela biopolítica com uma nova forma de não apenas consumir estética, mas de fruir de sua capacidade de reconstrução de identidades hoje fragmentadas.

\section{Referências}

ARANTES, Pedro Fiori. Arquitetura na Era Digital-Financeira: Desenho, Canteiro e Renda da Forma. São Paulo: Editora 34, 2012.

BENJAMIN, Walter. A obra de arte na época de sua reprodutibilidade técnica (Primeira versão). In: BENJAMIN, Walter. Obras Escolhidas. Magia, Técnica, Arte e Política. Tradução de Sérgio Paulo Rouanet. São Paulo: Brasiliense, 1987.p.165-196.

BENJAMIN, Walter. Paris capital do século XIX. In: KOTHE, Flávio (Org.). Walter Benjamin. Coleção Grandes Cientistas Sociais. São Paulo: Ática, 1985. p. 30-43.

BENJAMIN, Walter. Passagens. Belo Horizonte: Editora UFMG, 2007.

BOURDIEU, Pierre. A distinção: crítica social do julgamento. São Paulo: Edusp, 2007.

BOURDIEU, Pierre. Espaço físico, espaço social e espaço físico apropriado. In: Revista Estudos Avançados, v.27, n.79, p.133-144, 2013.

DARDOT, Pierre; LAVAL, Christian. A nova razão do mundo: ensaio sobre a sociedade neoliberal. São Paulo: Boitempo, 2016.

DEBORD, Guy. A sociedade do espetáculo. Rio de Janeiro: Contraponto, 1997.

DELEUZE, Gilles. Post-scriptum sobre as sociedades de controle. In: DELEUZE, Gilles. Conversações. Rio de Janeiro: Editora 34, 1992.

FOSTER, Hal. O complexo arte-arquitetura. São Paulo: Ubu Editora, 2017. FOUCAULT, Michel. Em defesa da sociedade. São Paulo: Martins Fontes, 2005. 
FOUCAULT, Michel. Microfisica do poder. Organização e tradução de Roberto Machado. Rio de Janeiro: Edições Graal, v. 4, 1979.

FOUCAULT, Michel. Nascimento da Biopolítica. Curso no Collège de France (1978-1979). São Paulo: Martins Fontes, 2008.

HARVEY. David. Condição pós-moderna. São Paulo: Edições Loyola, 1992. JACQUES, Paola Berenstein. Apologia da deriva. Rio de janeiro: Casa da Palavra, 2003.

LE CORBUSIER. Por uma arquitetura. São Paulo: Perspectiva, 1977.

LEFEBVRE, Henri. Espaço e política: O direito à cidade II. $2^{\mathrm{a}}$ ed. rev. e ampliada. Belo Horizonte: Editora UFMG, 2016.

LIPOVETSKY, Gilles; SERROY, Jean. A estetização do mundo: viver na era do capitalismo artista. São Paulo: Companhia das Letras, 2015.

LOOS, Adolf. Ornamento e crime. Lisboa: Edições Cotovia, 2004.

LYOTARD, Jean-François. A condição pós-moderna. Rio de Janeiro: Editora José Olympio, 1998.

MARINETTI, Filippo Tommaso. Fundação e manifesto do futurismo. In: BERNARDINI, Aurora Fornoni. O Futurismo italiano: manifestos. Coleção Debates. São Paulo: Editora Perspectiva, 1980. p. 31-36.

MORRIS, William. As artes menores e outros ensaios. Lisboa: Antígona, 2003.

MORRIS, William. The Collected Works of William Morris: Volume 22. Hopes and Fears for Art. Lectures on Art and Industry. Londres: Longmans green and company, 1910.

PEVSNER, Nikolaus. Origens da arquitetura moderna e do design. São Paulo: Martins Fontes, 1981.

Recebido em: 28 de outubro de 2018. Aprovado em: 06 de fevereiro de 2018. 